\title{
IRRADIATION CONDITIONS AFFECT THE QUALITY OF IRRADIATED PAINTED APPLE MOTH
}

\author{
A.E.A. STEPHENS ${ }^{1}$, A.M. BARRINGTON ${ }^{2}$, N.M. FLETCHER ${ }^{1}$ \\ and D.M. SUCKLING ${ }^{1}$ \\ ${ }^{1}$ HortResearch, PO Box 51, Lincoln, New Zealand \\ ${ }^{2}$ HortResearch, Private Bag 92 169, Auckland, New Zealand \\ Corresponding author: astephens@hortresearch.co.nz.
}

\begin{abstract}
Sterile painted apple moths have been released in Auckland in an attempt to assist with the eradication of this species from New Zealand. Quality, as measured by wind tunnel flight performance, of irradiated insects decreased from 66\% of un-irradiated males in 2003-2004 to approximately $43 \%$ in 2005-2006 and recapture rates were lower. A decrease in quality measures (i.e. emergence rate, wind tunnel flight performance and recapture rate) was related to an increase in the length of pre- and posttreatment time that the insects were held in the irradiation container, potentially caused by container conditions. Altering the irradiation container conditions to improve aeration led to an increase in posttreatment quality. The surveillance grid in place for monitoring caught the sterile moths. Higher recapture rates have increased confidence in the effectiveness of the sterile insect technique against this insect, which is continuing in south-eastern Auckland.
\end{abstract}

Keywords: sterile insect technique, painted apple moth, Teia anartoides, irradiation, fitness.

\section{INTRODUCTION}

The painted apple moth (PAM, Teia anartoides, Lepidoptera: Lymantriidae) was detected in Glendene, West Auckland, New Zealand, in April 1999 and a decision was made to eradicate the species because the economic and ecological impact of the PAM incursion was estimated at NZ\$50-350 million over 20 years (Self 2003). Application of aerial sprays of the biopesticide Bacillus thuringiensis var. kurstaki was used to suppress larval numbers (Richardson et al. 2005), while the sterile insect technique (SIT) was introduced in February 2003 once the pest population was brought down to $<1 \%$ of the population level in 2001-2002, as indicated by trap catches of adult males (Suckling et al. 2005). This West Auckland programme ended in April 2004.

The SIT programme was re-initiated in June 2005 after the discovery of a single male moth in Otahuhu (south-eastern Auckland) in late May, on the edge of the trapping grid in place for surveillance of PAM (delta traps baited with virgin females) in the Auckland area; the area monitored extended beyond the infestation zone. In the following year (June 2005-May 2006), another six males were caught in a range of locations around Auckland. Analysis of isotopic ratios present in these moths suggest that none were from Auckland and they had originated in a region more arid and/or at lower latitudes than Auckland (R. Frew, Isotrace NZ Ltd, pers. comm.). Three of these finds (August 2005, April 2006 and May 2006) were near the May 2005 catch, and none was in the previous West Auckland infestation zone. The Cobalt ${ }^{60}$ source used in both programmes was decaying, thus requiring longer exposure to achieve a dosage of $100 \mathrm{~Gy}$ during the 05/06 programme than during the 03/04 West Auckland programme. As a result of this, and the quarantine protocols required, pupae were held in the container for longer than previously. 
Lower emergence rates of irradiated moths, reduced flight performance and the lower recapture rates of irradiated moths strongly suggested that the quality of the moths released during the 05/06 programme was less than that of the moths released in the 03/04 West Auckland programme. For example, the fitness of the irradiated males had dropped from $66 \%$ to $43 \%$ of un-irradiated males, as measured by wind tunnel flight performance between May and December 2005. Kean et al. (2007) showed that more moths would need to be released, if the same level of control was to be obtained, as the fitness of the irradiated moths decreased. Minimising the loss of fitness is essential because insect rearing is a major cost in the PAM SIT programme (Wee et al. 2006).

It was noted that the fitness of moths that had been irradiated at the same dose in smaller batches in Petri dishes (for experimental use) was generally higher than those irradiated for release. This led to the hypothesis that the loss of fitness was due to the conditions experienced by the moths during irradiation rather than the irradiation per se. An experiment was designed to determine factors that would lead to an improvement in fitness of the SIT moths.

\section{Insects, irradiation and wind tunnel details}

In Experiment 1, PAM from the HortResearch colony were used. The SIT programme used moths from both the HortResearch and Ensis colonies to maximise the number of moths released. Both colonies originated from the West Auckland population and were reared on an artificial diet (A. Barrington, unpubl. data). Irradiation to $100 \mathrm{~Gy}$ was achieved using $1.25 \mathrm{MeV}$ gamma rays from a Cobalt ${ }^{60}$ source at the National Radiation Laboratory, Christchurch (Suckling et al. 2005). Insects are irradiated as pupae and released as newly emerged adult moths.

Wind tunnel flight performance of irradiated and un-irradiated male moths has been used to generate a measure of moth fitness (Suckling et al. 2004). In all cases, adult male moths were flown for two minutes in groups of five to a calling virgin adult female moth at the upwind end of the wind tunnel. Air in the wind tunnel (flight section $=55 \times 86 \times 196 \mathrm{~cm})$ was blown by a horizontal fan (Fischbach, $\mathrm{GmbH}$, Neunkirchen, Germany) with a wind speed of $0.5 \mathrm{~m} / \mathrm{s}$ onto 24 activated charcoal filters $(14.5 \times 32.5 \mathrm{~cm}$, Camfil, Trosa, Sweden). The exiting air was aspired by an exhaust fan and cleaned by two sets of charcoal filters at the downwind end of the tunnel before recirculation. The wind tunnel was lit from above and the temperature inside the wind tunnel maintained at $25-26^{\circ} \mathrm{C}$.

\section{Experiment 1 - impact of irradiation conditions}

This experiment was designed to determine whether the conditions that moths experienced during irradiation were causing a decrease in fitness. The flight performance of the moths irradiated in the standard irradiation container used for PAM SIT releases (a 2 litre ice-cream container; density approximately 5000 pupae/litre) was compared with that of moths irradiated in a $160 \mathrm{ml}$ plastic Petri dish attached to the outside of the main container (density 375 pupae/litre). The pupae were held in the irradiation containers for similar lengths of time. At each event, 60 pupae were retained as control and the rest were exposed to irradiation, 60 in the Petri dish and the rest in the 2 litre ice cream container. After irradiation a subsample of 60 pupae were taken from the centre of the ice cream container. All pupae emerged within a day of each other and all adult moths were flown in the wind tunnel.

\section{Monitoring the SIT programme}

The standard 2 litre container in which the PAM were irradiated ("unvented") was modified, following the results obtained in Experiment 1. Ventilation was increased with the placement of six mesh inserts into the sides of the container ("vented"). In addition, the vented irradiation container was placed onto a bed of silica crystals to further reduce the humidity around the container. Silica crystals would be unlikely to affect the irradiation dose (J. Laban, pers. comm.). 
Other than these changes, the SIT irradiation and release procedure were conducted as previously. Three measures of adult moth fitness, healthy emergence, recapture rates and wind tunnel flight performance, were made to ascertain the impact of these modifications.

The proportion of healthy irradiated adult moths that emerged from both the HortResearch and Ensis colonies before and after the irradiation conditions were altered, was monitored to determine impact on the emergence rate. Healthy moths are defined as those which emerge being able to fly (Suckling et al. 2004). In total, 369,100 moths were monitored using the unvented container and 67,760 with the vented container (Table 1).

The trapping grid in place for surveillance consisted of virgin female baited traps, which also recaptured the sterile moths (Suckling et al. 2005). The recapture rate is an indicator of the quality of the released males. Although the SIT programme re-started in May 2005, recapture rates could only be compared from the summer months of the programme (December-March), as the low recapture results during winter were attributable to low daily temperatures (Suckling et al. 2005). During this period, 48,430 moths irradiated in the unvented container were released and 57,360 moths irradiated in the vented container (Table 1). Each release event was treated as a replicate.

A sample of 120 (60 control and 60 irradiated) moths from the HortResearch colony and 40 (20 control, 20 irradiated) moths from the Ensis colony were tested each week during the period 1 June 2005-5 April 2006 (Table 1). These sample sizes were based on pragmatic considerations, as a trade-off between minimising variance and potential impact on the SIT programme, as moths tested in the wind tunnel are not available for release.

\section{Data analysis}

In Experiment 1, the number of male moths reaching the female was recorded and the means were compared using ANOVA, followed by Tukeys HSD at $\mathrm{P}=0.05$.

During monitoring of the SIT programme, the pupae from each irradiation were separated into two groups, based on the age of the irradiated pupae, in order to achieve two releases per week at the same sites from one irradiation. Each of these releases was treated as a replicate. The percentage of healthy moths and the recapture rate for each release were calculated prior to and after the change in irradiation container. For the flight testing, one subset taken from each irradiation was treated as a replicate and percentage reaching female prior to and after the change in irradiation container was calculated. The data were arcsine transformed and compared using a Student t-test to ascertain if mean values within a colony were different as a result of the change in irradiation container. The relative flight fitness of the moths was calculated as: Relative flight fitness $=$ Irradiated moths reaching female/Un-irradiated moths reaching female.

\section{RESULTS \\ Experiment 1 - impact of irradiation conditions}

The percentage of moths reaching the female was significantly higher when irradiated in the Petri dish than the 2 litre container, and not significantly different to those that were not irradiated (Fig. 1), indicating that irradiation conditions experienced impacted on moth fitness.

\section{Monitoring the SIT release programme}

The number of the moths from both colonies that emerged able to fly significantly increased following the modification of the irradiation container (Table 1). The general activity level of the moths that emerged from the vented container was visibly higher than previously, but this was not quantified.

The percentage of moths recaptured was greater for those irradiated in the vented container than those from the un-vented one (Table 1) for both HortResearch and Ensis colonies. The increased recapture rates indicates greater ability to locate wild females, thus has lead to increased confidence in the effectiveness of the SIT programme. 


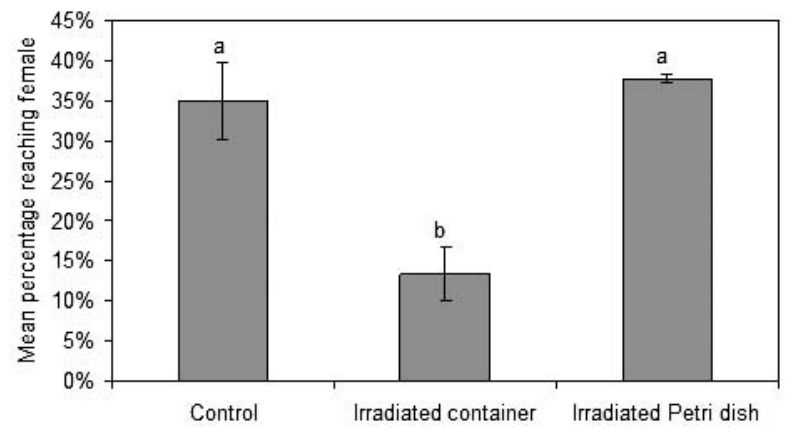

FIGURE 1: Mean $( \pm$ SEM) percentage of painted apple moths that reached the female in a wind tunnel when irradiated in a 2 litre container, the Petri dish or un-irradiated moths. Different letters above the bars indicate treatments that were significantly different at $\mathbf{P}<0.05$.

TABLE 1: Percentage of moths with healthy emergence (emerged able to fly), recapture rate (percentage of released moths recaptured) and percentage of males reaching female in wind tunnel flight tests recorded from painted apple moths using vented and un-vented containers during irradiation treatment. Values presented are (mean \pm SEM) for the HortResearch and Ensis colonies along with the number of irradiation/releases and the total number of PAM irradiated, released or flown in the wind tunnel during the monitoring period.

\begin{tabular}{|c|c|c|c|}
\hline & Un-vented container & Vented container & P-value \\
\hline \multicolumn{4}{|c|}{ Healthy emergence } \\
\hline HortResearch & $\begin{array}{c}67 \text { releases, } 208,900 \text { pupae } \\
64.45 \% \pm 2.98\end{array}$ & $\begin{array}{c}14 \text { releases, } 37,240 \text { pupae } \\
94.65 \% \pm 1.19\end{array}$ & $<0.001$ \\
\hline Ensis & $\begin{array}{c}68 \text { releases, } 160,200 \text { pupae } \\
45.28 \% \pm 2.76\end{array}$ & $\begin{array}{c}12 \text { releases, } 30,520 \text { pupae } \\
72.94 \% \pm 2.70\end{array}$ & $<0.001$ \\
\hline \multicolumn{4}{|l|}{ Recapture rates } \\
\hline Hort & $\begin{array}{c}16 \text { releases, } 33,630 \text { moths } \\
0.49 \% \pm 0.20\end{array}$ & $\begin{array}{c}13 \text { releases, } 35,300 \text { moths } \\
1.48 \% \pm 0.40\end{array}$ & 0.028 \\
\hline Ensis & $\begin{array}{c}16 \text { releases, } 14,800 \text { moths } \\
0.34 \% \pm 0.18\end{array}$ & $\begin{array}{c}12 \text { releases, } 22,060 \text { moths } \\
2.40 \% \pm 0.92\end{array}$ & 0.019 \\
\hline \multicolumn{4}{|c|}{ Wind tunnel flight performance } \\
\hline HortResearch & 35 irradiations, 4200 moths & diations, 840 moths & \\
\hline & $12.33 \% \pm 1.46$ & $20.10 \% \pm 3.72$ & 0.04 \\
\hline Un-irr & $29.33 \% \pm 1.83$ & $35.10 \% \pm 3.53$ & 0.20 \\
\hline Relative fitness $^{1}$ & $42 \%$ & $57 \%$ & \\
\hline Ensis & 35 irradiations, $1400 \mathrm{~m}$ & 6 irradiations, 420 moths & \\
\hline Ir & $9.49 \% \pm 2.14$ & $13.06 \% \pm 4.51$ & 0.55 \\
\hline Un-irradiated & $21.30 \% \pm 2.44$ & $19.17 \% \pm 5.55$ & 0.74 \\
\hline Relative fitness $^{1}$ & $44 \%$ & $68 \%$ & \\
\hline
\end{tabular}

${ }^{1}$ Relative flight fitness=Irradiated moths reaching female/Un-irradiated moths reaching female. 
The percentage of irradiated moths that reached the female increased for PAM from the HortResearch colony using the vented containers (Table 1). The percentages of moths from the Ensis colony were not significantly different between container types. However, in both colonies, the Relative fitness increased (Table 1). There was no change in the proportion of un-irradiated moths reaching the females, and therefore other changes made to the regime are unlikely be responsible for the increase in flight fitness.

\section{DISCUSSION}

Quality measures of the moths released as part of the 2005-06 PAM SIT programme in Auckland were less than moths released during the 2003-04 programme. Three measures of quality were used, healthy emergence, recapture rates and wind tunnel flight performance of the adult moths. It was noted that moths irradiated in Petri dishes did not suffer the same reduction in quality as moths irradiated in the standard irradiation container. This suggested that the irradiation per se was not causing the damage, but rather the conditions experienced by the moths during irradiation. To rectify the decrease in quality from the irradiation conditions, vents were added to the irradiation container and quality measures following this change were monitored. All quality measures increased in the HortResearch colony but the wind tunnel flight performance did not increase in the Ensis colony. Recapture rate ultimately is the most important of the quality measures as it is a direct measure of the ability of irradiated moths to successfully locate wild females. Venting of the container was the most likely explanation for the increase in recapture rate, as other measures of fitness and quality also increased with the container change and the increases were sustained. However, other factors could play a role, such as release sites, trap numbers and spacing. The operational nature of the PAM SIT programme meant these factors were not constant across assessments. Additionally, weather conditions may also have played a role in the difference in recapture rate.

While a significant increase in the fitness of the moths was achieved by the combination of increased ventilation of the irradiation container and presence of silica crystals in the chamber, requirements of the irradiation procedure meant it was not possible to determine the mechanisms causing the change. However, presumably humidity and $\mathrm{CO}_{2}$ levels decreased, and oxygen increased in the environment experienced by the pupae in the vented container.

Relatively few investigations into the sterile insect technique have determined how damage occurs during irradiation. Irradiation of insects in most SIT programmes is normally achieved very rapidly by high dose gamma sources (Bakri et al. 2005b), rather than the small-scale source used here. The quality problem faced in this SIT programme was a result of the time taken to achieve the desired level of irradiation, which was substantially longer (hours) than it would be in a purpose-built SIT irradiation facility (seconds or minutes to achieve dosimetry).

While little work has been done investigating the impact of RH during insect irradiation, Bakri et al. (2005a) listed humidity and ventilation among the factors that may lead to inconsistent results between studies. It is widely known that hypoxic (low oxygen) cancer cells can be made more sensitive to irradiation by increasing the oxygen supply (Proacta 2005). This knowledge has been applied to the use of irradiation for quarantine purposes. Low oxygen conditions require a higher radiation dose to achieve the same level of mortality as irradiation in air (Hallman 2000). Lowered fitness of PAM in low oxygen conditions suggests greater damage and therefore is inconsistent with the other studies. The $\mathrm{CO}_{2}$ released during respiration may have had a narcotic effect on the moths, but whether this could have had an impact on subsequent fitness is unknown.

The decrease in RH caused by the venting of the irradiation container could explain the increase in fitness. Some authors have proposed host moisture content to explain differences in radiation dose required for quarantine treatment. For example, Follet \& Neven (2006) reported that fruit variety had a dramatic impact on egg hatch and larval development during irradiation studies in Mediterranean fruit fly (Ceratitis captitata) in nectarines and plums, with fruit moisture content being suspected as the causative factor. 
A change in temperature in the container as a result of endogenous metabolic heat was also a possible factor in the change in fitness. However, no change in time to emergence was noted, which might have been expected if a reduction in metabolic heat was implicated in the increase in fitness.

Optimising fitness of moths for a sterile insect programme is crucial to maximise the chances of success of eradication. This work has shown that irradiation conditions affect moth fitness. Maximising the competitive fitness of irradiated insects is important to the success and cost-effectiveness of the sterile insect technique, and the new container has been adopted. Environmental conditions during irradiation need to be considered when designing an irradiation procedure for the sterile insect technique or disinfestation of commodities, to achieve the desired results.

\section{ACKNOWLEDGEMENTS}

We would like to thank Pauline Boxen, Vicky Bush, Natalie Page, Asha Chhagan, Kirsty Boyd-Wilson and Lloyd Stringer for their work in various aspects of the SIT programme, Pam Taylor and team at Ensis for supply of insects, AgriQuality for servicing the traps and Johnny Laban and the staff at the National Radiation Laboratory for irradiating the insects. Suk Ling Wee, Dave Rogers and Anne Gunson gave helpful comments on a draft of this paper. Biosecurity New Zealand and the New Zealand Foundation for Research, Science and Technology programme "Better Border Biosecurity" funded this work.

\section{REFERENCES}

Bakri A, Heather N, Hendrichs J, Ferris I 2005a. Fifty years of radiation biology in entomology: lessons learnt from IDIDAS. Annals of the Entomological Society of America 98 (1): 1-12.

Bakri A, Mehta K, Lance DR 2005b. Sterilizing insects with ionizing radiation. In: Dyck VA, Hendricks J, Robinson AS ed. Sterile Insect Technique. Principles and Practice in Area-Wide Integrated Pest Management. Springer, Dordrecht, The Netherlands. Pp. 233-268.

Follet PA, Neven LG 2006. Current trends in quarantine entomology. Annual Review of Entomology 51: 359-385.

Hallman GJ 2000. Expanding radiation quarantine treatments beyond fruit flies. Agricultural and Forest Entomology 2: 85-95.

Kean JM, Stephens AEA, Wee SL, Suckling DM 2007. Optimising strategies for eradication of discrete-generation Lepidopteran pests using inherited sterility. In: Vreysen MJB, Robinson AS, Hendrichs J ed. Area-Wide Control of Insect Pests: From Research to Field Implementation. Springer, Dordrecht, The Netherlands. In press.

Proacta 2005. http://www.proactatherapeutics.com/ (accessed 02 May 2006).

Richardson B, Kay MK, Kimberley MO, Charles JG, Gresham BA 2005. Evaluating the benefits of dose-response bioassays during aerial pest eradication operations. New Zealand Plant Protection 58: 17-23.

Self M 2003. Biosecurity: the implications for international forestry trade. The Australian and New Zealand Institutes of Forestry Conference, Queenstown, New Zealand. Pp. 59-63.

Suckling DM, Charles J, Allan D, Chaggan A, Barrington A, Burnip GM, El-Sayed AM 2005. Performance of irradiated painted apple moth (Lepidoptera: Lymantriidae) in urban Auckland, New Zealand. Journal of Economic Entomology 98: 1531-1538.

Suckling DM, Pedley R, Wee SL 2004. Pupal age affects efficacy of irradiation on painted apple moth Teia anartoides. New Zealand Plant Protection 57: 166-170.

Wee SL, Kean JM, Stephens AEA, Suckling DM 2006. Evaluation of the costeffectiveness of sterile insect release strategies against painted apple moth, Teia anartoides. New Zealand Plant Protection 59:109-118. 